\section{El encanto de editar una revista médica y los recuerdos nostálgicos al alejarme}

\author{
HUMBERTO REYES B.
}

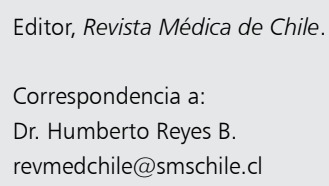

\section{The fascination of editing a medical journal and the nostalgic memories when departing}

As of March 2016, Humberto Reyes, MD, FACP, steps down as Editorin-Chief of Revista Médica de Chile. He joined its editorial team in 1971, as a part-time Assistant Editor. A few years later he became Associate Editor and since 1996, Editor-in-Chief. During his tenure the journal improved the peer review system and implemented a web platform to handle the editorial process, while following the recommendations established by acknowledged organizations such as the International Committee of Medical Journal Editors (ICMJE), the World Association of Medical Journal Editors (WAME) and the Committee on Publication Ethics (COPE). Since 2010 he represented Revista Médica de Chile as an ICMJE Member. After an open contest, the Sociedad Médica de Santiago, founder and owner of Revista Médica de Chile since 1872, elected Fernando Florenzano MD as the new Editor-in-Chief. Dr. Reyes leaves this long lasting job with the satisfaction of having conducted an institution considered among mainstream medical journals in spite of being mostly published in Spanish. Revista Médica de Chile receives a high proportion of the research articles that have been generated in the country, subsequently handled by an enthusiastic and solid editorial team whose responsibilities go far beyond selecting the material to be published since they are medical educators striving to help authors to improve their papers before having them published. Conducting this journal has been a fascinating task for this Editor as well as an unforgettable experience.

(Rev Med Chile 2016; 144: 281-284)

Key words: Biomedical publications; Chile; Journals, medical; Peer review; Periodicals as topic.

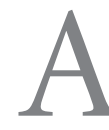

comienzos de la década de 1960, siendo Residente-becario de Medicina Interna, ingresé en categoría de socio a la Sociedad Médica de Santiago. Además de cumplir con entusiasmo las responsabilidades de asistir a las reuniones científicas y congresos, presentar trabajos de investigación, entregar manuscritos para publicación, sentí muy temprano un interés creciente por participar en el proceso de edición de su revista, la Revista Médica de Chile.

En 1966 empecé a participar en la Revista, reemplazando por algunos meses al Dr. Alejandro Goic, editor adjunto, durante su alejamiento temporal cumpliendo una beca en los Estados Uni- dos de Norteamérica. Guiado por el Dr. Ernesto Medina, otro de los editores, inicié mi aprendizaje de cómo revisar y corregir manuscritos. El Dr. Medina aplicaba su buen criterio y conocimientos de la medicina al juzgar el contenido y formato de los manuscritos que entonces se recibían en papel, dactilografiados con máquinas de escribir. Frente a las tablas de datos aplicaba su sólida formación en bioestadística revisándolas utilizando una "regla de cálculos", instrumento diabólico diseñado por ingenieros y matemáticos, que nunca logré dominar. El editor jefe ("Director") era el Dr. Werner Roeschmann von Bischoffhausen, cuyos ancestros germánicos y su formación como internista en el 
Servicio y Cátedra del Profesor Hernán Alessandri se sumaban en la toma de decisiones. Era habitual encontrarlo a la salida de las reuniones científicas de la Sociedad estimulando a los autores que habían presentado algún trabajo interesante (a juzgar por los aplausos del público y los comentarios positivos de los grandes profesores) para que lo convirtieran en uno de los artículos que recibía la Revista. Si lo conseguía (generalmente al cabo de meses de paciente espera), podía incluirlo en alguno de sus números mensuales, que se publicaban con ochenta a noventa páginas cada uno y aparecían impresos tres a cuatro meses después de la fecha presunta de publicación. Pocas personas (los Drs. Roeschmann, Medina, Goic y ahora, transitoriamente, Reyes) revisaban y seleccionaban los manuscritos, y los corregían hasta considerarlos aptos para ser publicados. Si bien podían solicitar a los autores que rehicieran sus manuscritos, corrían el riesgo de no recuperarlos, por lo cual muchas veces los "mejoraban" ellos mismos (empezando por la sintaxis y la ortografía) y el propio Dr. Roeschmann redibujaba los gráficos en una mesa de diseñador gráfico, utilizando un pantógrafo, papel "mantequilla" y "tinta china negra". Sólo muy ocasionalmente se solicitaba la opinión de un especialista externo, utilizando el teléfono y los servicios de un mensajero que repartía y recogía los documentos hacia los cuatro puntos cardinales de Santiago, viajando en "micro" o "trole", como se llamaban entonces los vehículos de transporte público. Conseguir opiniones desde Valparaíso o Concepción exigía recurrir a la empresa de correos, además de onerosas llamadas telefónicas "de larga distancia”, con intervención de "operadoras", tiempos de espera y buena suerte para coincidir a esa hora con la presencia del interlocutor buscado.

Años después, en junio de 1971, habiendo retornado de mi beca para investigación en fisiopatología hepática, en Nueva York, fui invitado a incorporarme como editor adjunto de la Revista, porque el Dr. Medina había renunciado para asumir la Dirección de la Escuela de Salud Pública. Los contratos a honorarios identificaban nuestras funciones como "compaginadores de la Revista Médica de Chile".

Durante los cuarenta y un años siguientes, una parte muy querida de mi carrera profesional transcurrió en esta institución, en sus sedes sucesivas en calle Esmeralda, avenida Presidente
Riesco y calle Bernarda Morín. Alejandro Goic y yo éramos responsables de la edición de la Revista, mientras hasta 1973 los Dres. Ricardo Cruz Coke y Oke France colaboraban en otros aspectos. Sin embargo, el flujo creciente de manuscritos, llegando ahora a más de 350 al año, y la complejidad progresiva del proceso editorial (en el año 2014 intervinieron 543 personas en la revisión por pares externos) hizo obviamente indispensable contar con más editores.

La Revista Médica de Chile sigue normas y recomendaciones establecidas por prestigiadas entidades tales como el International Committee of Medical Journal Editors (ICMJE), la World Association of Medical Journal Editors (WAME) y el Committee on Publication Ethics (COPE), determinando que la Revista pertenezca a la "corriente principal" de las publicaciones científicas. En los años recientes se implementó progresivamente una plataforma web bilingüe en la que se concentra el proceso editorial, desde la recepción de los manuscritos "subidos" por sus autores hasta su traspaso a la empresa que imprime la revista y prepara su versión on line.

Entre 1991 y 2001 participó como Editor Asociado el Dr. Ronald Kauffmann quien, además, fue autor principal o coautor en estudios sobre la preparación de manuscritos y su selección en la Revista, hasta que nuevos atractivos laborales lo indujeron a retirarse. En 1997 se incorporó el Dr. Max Andresen, en 2002 el Dr. Joaquín Palma (en la vacante dejada por el doctor Kauffmann) y en 2014 el Dr. Ricardo Castro.

La inclusión de la Revista en bases de datos internacionales, como MEDLINE/PubMed, hizo necesario perfeccionar los resúmenes en inglés para facilitar la visibilidad internacional de los manuscritos. En el transcurso de los años, sólo una minoría de los autores ha mostrado competencia para ofrecer resúmenes adecuados en su formato y contenido, y en un inglés correcto. Para mejorar este aspecto, se solicitó la colaboración de docentes con formación bilingüe, contando con la participación sucesiva de las Dras. Ana María Kaempffer y María Eugenia Radrigán, los Dres. Gonzalo Álvarez, Gastón Chamorro Spikin y Daniel Bunout, este último con rango de Editor de Resúmenes en Inglés, considerando que su labor excede la traducción de los resúmenes que aportan los autores.

En julio de 1996 el Dr. Alejandro Goic puso término a su labor como Editor Jefe, después de 


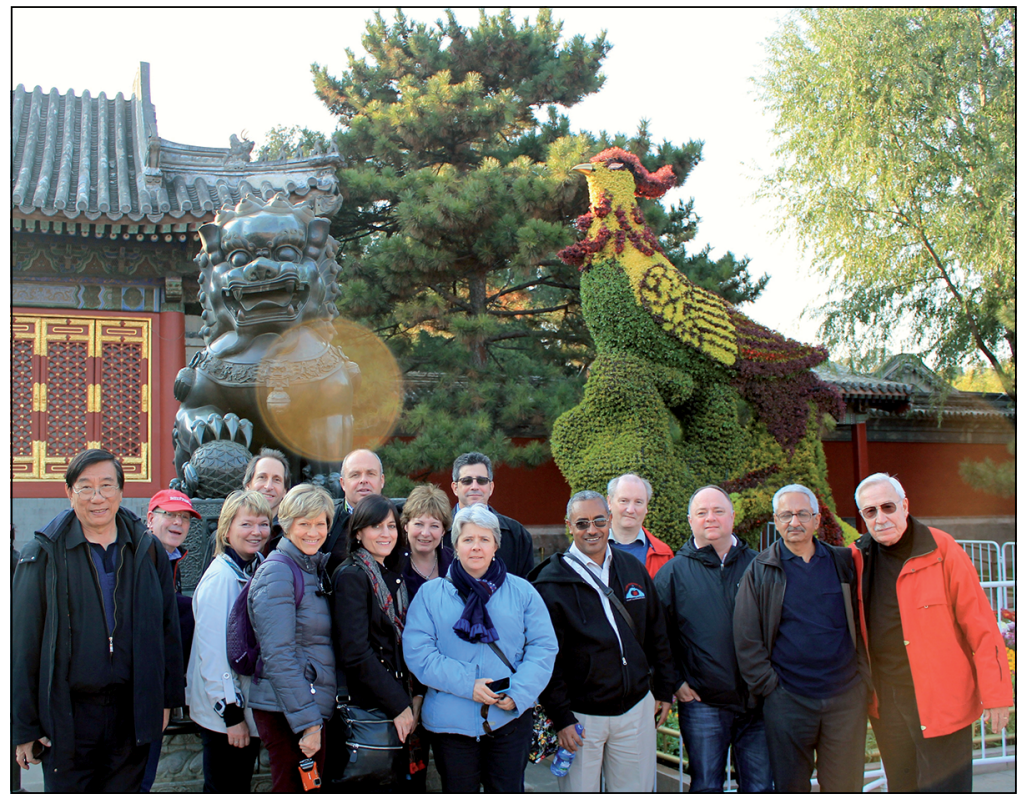

Fotografía. Beijing, noviembre de 2014. En el Palacio Imperial de Verano: Getu Zhaori, Chinese Medical Journal; Jeffrey Drazen, New England Journal of Medicine; Charlotte Haug, Norwegian Medical Journal (Tidsskrift for Den norske legeforening); Darren Taichman, Annals of Internal Medicine, Secretario del Comité; Joyce Backus, National Library of Medicine; Frank Frizelle, New Zealand Journal of Medicine; Christine Laine, Annals of Internal Medicine; Astrid James, The Lancet; Virginia Barbour, PLOS Medicine; Howard Bauchner, JAMA; Abraham Amlak, Ethiopian Journal of Health Sciences; John Fletcher, Canadian Medical Association Journal; Jacob Rosenberg, Journal of Danish Medical Association; Peush Sahni, World Association of Medical Journal Editors (WAME); Humberto Reyes, Revista Médica de Chile. Ausentes: Fiona Godlee, British Medical Journal; Peter de Leeuw, Dutch Medical Journal (Nederlands Tidjdschrift voor Geneeskunde). Como fondo: Parte del frontis del palacio; el león simboliza al Emperador dominando al Mundo (el globo terráqueo bajo su pata derecha); el ave con arbustos multicolores representa al extenso territorio de China continental, con sus provincias y regiones, incluyendo (cabeza) el Tibet.

veintiséis años de brillante desempeño en que consiguió profesionalizar la función de los editores y del personal de secretaría, convirtiéndolos en un equipo que tiene vocación de servicio hacia los autores y los revisores de manuscritos. En su reemplazo, el Directorio de la Sociedad Médica de Santiago me nombró con un contrato a honorarios "por un lapso de cinco años, renovable una sola vez", cláusula que posteriormente nadie recordó. Durante diecinueve años cumplí esta función con cariño, honestidad, buena fe y empeño, hasta que en diciembre de 2014 comuniqué a la Mesa Directiva de la Sociedad mi intención de ponerle término, dando tiempo al Directorio para planificar y ejecutar un proceso de búsqueda que culminó con un llamado a concurso público, en el que fue seleccionado para sucederme el Dr. Fernando Florenzano Urzúa. El Dr. Florenzano es un distinguido internista, cardiólogo y docente universitario a quien he tenido el privilegio de conocer desde que fuera alumno e interno de medicina, y luego residente-becario, hasta adquirir certificación de la especialidad y subespecialidad que ejerce. Tengo plena confianza en que su buen criterio, sapiencia y honestidad impulsarán cambios promisorios mientras sostendrá los logros ya alcanzados.

Lo realizado durante mis cuarenta y un años en la Revista y como Editor Jefe en los últimos diecinueve, está a la vista de los lectores y autores de manuscritos. La experiencia adquirida por el equipo editorial fue analizada en artículos publicados en la Revista. Nuestra participación en el International Committee of Medical Journal Editors (ICMJE) nos dio una grata y honrosa oportunidad para intervenir en las discusiones de un grupo señero de editores de revistas médicas generales y organismos afines (National Library of Medicine, WAME), autores de las ICMJE Recommendations, el documento más relevante que guía el proceso editorial (Fotografía). Tuvimos la grata opor- 
tunidad de brindar Santiago como sede para su reunión en noviembre de 2013, bajo el patrocinio y hospitalidad de la Sociedad Médica de Santiago.

En esta despedida no haré mención de múltiples anécdotas vividas como Editor, algunas alegres y otras tristes. Sólo "el cómo se consiguió el ingreso a ISI Web of Science" daría para un relato entretenido, aunque inapropiado para esta ocasión $y$ en una revista tan seria.

Cumplo el grato deber de agradecer la cohesión del equipo de editores: Max, Joaquín, Ricardo, Daniel, aportando su trabajo responsable y colaboración educativa para los autores y los revisores de manuscritos. Así también agradezco la abnegación, eficiencia y espíritu de servicio de las Secretarias, Sras. Ximena Quinteros e Isabel Martínez, el Auxiliar Sr. Óscar Osses y nuestro webmaster, Sr. Ítalo Costa. La Sra. Ximena ha sido invaluable durante mi período como Editor Jefe, actuando, al decir de Max Andresen, como "editorial manager" además de secretaria. Los sucesivos impresores de la Revista: Gaete Hnos. y Editorial IKU Ltda., han sido excelentes colaboradores.

También debo agradecer a una larguísima lista de Directores y autoridades de la Sociedad Médica de Santiago que durante estos históricos ciento cuarenta y tres años han apoyado a la Revista Médica de Chile como si fuera su hija más preciada (y lo es), respetando siempre la independencia de los editores para conducirla. En lo que respecta a mi período editorial, su comprensión y respaldo han sido permanentes y fructíferos. Tal vez no pueda perdonarles haberme nombrado "Director invitado", por lo cual tuve que asistir a incontables reuniones mensuales, en horas vespertinas, en las que muchas, demasiadas veces, discutieron latamente lo mismo que habían discutido otros Directorios en años previos, por no haber leído las actas respectivas. Ser "memoria institucional" no siempre es entretenido.

En octubre de 2001, para su congreso anual, la Sociedad Médica de Santiago me invitó a dar una conferencia enfocada en mi labor como Editor. El título que elegí para esa oportunidad fue " $E l$ encanto de editar una revista médica". Eso es, precisamente, lo que siento hoy al alejarme de ella: he sido víctima de un encantamiento, pero estoy feliz de haberlo sido. 